\title{
Effect of diabetes mellitus on mouse pre-implantation embryo development
}

\author{
K. H. Moley ${ }^{1, *}$, W. K. Vaughn ${ }^{2}$, A. H. DeCherney ${ }^{1}$ and M. P. Diamond ${ }^{1} \dagger$ \\ ${ }^{1}$ Division of Reproductive Endocrinology, Department of Obstetrics and Gynecology, Yale \\ University School of Medicine, New Haven, CT 06510, USA; and ${ }^{2}$ United Network for Organ \\ Sharing, Richmond, VA 23225, USA
}

\begin{abstract}
Summary. Fifteen spontaneously diabetic, non-obese mice (NOD strain), 17 nondiabetic NOD mice (in which diabetes had not yet developed) and 9 diabetic NOD mice were treated with insulin. All animals were superovulated with 5 iu of pregnant mares' serum gonadotrophin followed $48 \mathrm{~h}$ later by $5 \mathrm{iu}$ human chorionic gonadotrophin (hCG) and mated overnight with NOD males of proven fertility. To assess in-vitro and early in-vivo development, 23 NOD mice were killed $72 \mathrm{~h}$ after hCG treatment. Embryos were recovered from oviduct flushings and cultured in Ham's F-10 medium with $0.1 \%$ bovine serum albumin at $37^{\circ} \mathrm{C}$ in an atmosphere of $5 \% \mathrm{O}_{2}, 5 \% \mathrm{CO}_{2}$, and $90 \% \mathrm{~N}_{2}$. Development was assessed at intervals of $24 \mathrm{~h}$ for $72 \mathrm{~h}$. Compared with embryos from non-diabetic NOD mice $(n=81)$, embryos from diabetic NOD mice $(n=68)$ demonstrated marked impairment in growth assessed by distribution of developmental stages at each observation period $(24,48,72 \mathrm{~h}$, all $P<0.001)$ and by overall rates of progression of developmental stages $(P<0.01)$. In diabetic NOD mice treated with insulin, embryo development $(n=71)$ was not significantly different from that of embryos from non-diabetic NOD mice $(n=81)$, but was significantly faster than in embryos from diabetic NOD mice not treated with insulin $(n=68)(P<0.001$, for all periods, overall rate $P<0.01$ ). To assess late in-vivo growth, 18 NOD mice were killed $120 \mathrm{~h}$ after hCG. Distribution of developmental stages was significantly retarded among embryos from diabetic NOD mice $(n=115)$ compared with embryos from nondiabetic NOD mice $(n=117)(P<0.001$ at all times $)$, and with embryos from NOD diabetic mice treated with insulin $(n=29)(P<0.001)$. We therefore conclude that uncontrolled spontaneous diabetes mellitus per se retards embryo development of mice in vivo and in vitro.
\end{abstract}

Keywords: development; mouse; pre-implantation embryos; diabetes mellitus; NOD

\section{Introduction}

An uncontrolled state of maternal diabetes mellitus adversely affects the fetus in the later stages of pregnancy, manifested as respiratory distress syndrome and late intrauterine death (Kitzmiller et al., 1978; Diamond et al., 1985, 1987). Infants of poorly controlled diabetic mothers also have higher rates of severe congenital malformations, including caudal regression syndrome, cardiac anomalies and neural tube defects (Simpson et al., 1983; Diamond et al., 1986). The incidence of late complications can be markedly reduced with the institution of meticulous glucose control during pregnancy (Coustan et al., 1980; Jovanovic et al., 1981). The rate of malformations is also

\footnotetext{
*Present address: Department of Obstetrics and Gynecology, Washington University School of Medicine, St Louis, MO 63110, USA.

$\nmid$ Reprint requests.
} 
lowered with the administration of insulin and lowering of blood glucose concentrations during organogenesis. However, knowledge of manifestations of diabetes on earlier stages of pregnancy is limited.

Several reports suggest an increased incidence of spontaneous abortion in diabetic women and a lowering of this incidence with improvement in metabolic control (Sheridan-Pereira et al., 1983; Miodovnik et al., 1984, 1985). Clinical studies also report early fetal growth retardation at 7-14 weeks of gestation in infants of diabetic mothers, an event occurring early and perhaps overlooked because of the late macrosomic effect in the hyperinsulinaemic state during the later pregnancy (Pederson \& Molsted-Pederson, 1979, 1981). Similar reports of early fetal wastage and reduced reproductive performance have also been reported in vivo among induced and spontaneous diabetic animal models (Lawrence \& Cantalopoulos, 1960; Johnson \& Sidman, 1979; Diamond et al., 1989). A causal mechanism for these deleterious events is unknown. An investigation of the period of preimplantation embryo development, therefore, is essential to the understanding of reproductive performance in diabetics.

We have shown that prolonged, chemically induced, maternal diabetes impairs subsequent oocyte maturation as well as the development of mouse pre-implantation embryos both in vivo and in vitro for $72 \mathrm{~h}$ (Diamond et al., 1989). These maturational delays seen in embryos from diabetic animals were partly ameliorated with maternal in-vivo insulin therapy. In these previous studies, diabetes was induced by intraperitoneal injection of alloxan or streptozotocin. Two diabetogenic agents were used to minimize the possibility that the results seen were due to a drug-induced embryotoxic effect of one of the drugs. The reversal of the growth retardation with better maternal glycaemic control further implicates the metabolic derangement of the uncontrolled diabetic state as the primary factor responsible for the delay in oocyte maturation and pre-implantation embryo growth retardation. None the less, these experiments do not exclude the possibility that both alloxan and streptozotocin exert toxic effects on the developing oocyte and later on the embryo.

In the current study, we attempted to avoid the potential confounding effects of chemically induced diabetes by assessing pre-implantation embryo development in non-obese diabetic (NOD) mice. This inbred strain develops autoimmune insulin-dependent diabetes that bears a striking resemblance to the human disease (Makino et al., 1980; Kano et al., 1986). Diabetes occurs predominantly in females, which show a lower parturition rate than non-diabetic females (Makino et al., 1981). Little is known about the reproductive performance of these diabetic animals or how their spontaneous diabetic state affects embryo development. The data have been, in part, published in abstract form (Moley et al., 1989).

\section{Materials and Methods}

The female mice were from the non-obese diabetic (NOD) strain bred at the Howard Hughes Laboratory for Immunological Research at Yale University and kindly provided by $C$. Janeway and P. Reich. The animals ranged in age from 6 weeks to 12 months: 18 were used for the late $(120 \mathrm{~h})$ in-vivo study (Group 1$)$ and 23 for the in-vitro and earlier (72 h) in-vivo investigation (Group 2). Since not all NOD mice became diabetic before they were studied, we were able to use non-diabetic littermates as direct controls for the diabetic animals. If no littermate existed, non-diabetic, agematched NOD mice were used. In Group $1(n=18), 10$ non-diabetic NOD mice served as controls for the 8 diabetic NOD mice, 2 of which were treated with insulin. To check that embryo development in non-diabetic NOD mice was not different from that in mice of a well-characterized strain, $9 \mathrm{~F}_{1}$ hybrid mice (between the inbred strains C57BL/6 and $\mathrm{C} 3 \mathrm{H})$ were used as controls. In Group $2(n=23), 7$ mice were non-diabetic NOD animals, 9 were diabetic NOD animals and 7 were diabetic NOD animals treated with insulin; $17 F_{1}$ hybrid non-diabetic mice served as non-NOD controls.

Mice were given free access to food and water and kept in a $12 \mathrm{~h}$ light: $12 \mathrm{~h}$ dark cycle. In all mice, superovulation was induced with an intraperitoneal injection of 5 iu pregnant mares' serum gonadotrophin (PMSG)/animal (Gestyl: Organon, Oss Netherlands), followed $48 \mathrm{~h}$ later by 5 iu human chorionic gonadotrophin (hCG)/animal (Pregnyl: Organon) to simulate an in-vivo surge in luteinizing hormone ( $\mathrm{LH})$. Female mice were mated with males of proven fertility on the night of hCG injection. Mating was confirmed by identification of a vaginal plug.

Animals were screened for the onset of diabetes mellitus using dipsticks for urine glucose and ketone measurements (Keto-Diastix: Ames, Elkhart, IN, USA). The diagnosis was confirmed by serum glucose measurements of 
$\geqslant 180 \mathrm{mg} / \mathrm{dl}$ by bloodstrips (Chemstrip: Becton-Dickinson, Rutherford, NJ, USA) and/or by glucose analysis using a Beckman Glucose Analyzer II (Beckman Instruments Inc., Fullerton, CA, USA). Subsequently, diabetic control was monitored by the same methods. Blood glucose was also determined when non-diabetic and diabetic mice were killed. Blood glucose concentrations in diabetic mice were $\geqslant 180 \mathrm{mg} / \mathrm{dl}$ before PMSG injections were begun; those in all non-diabetic NOD and $F_{1}$ hybrid mice ranged from 40 to $120 \mathrm{mg} / \mathrm{dl}$. In all except 5 of the diabetic animals, 10 days to 2 weeks intervened between the onset of the diabetic state and the initiation of superovulation with PMSG. The other 5 mice had been diabetic for 4-8 weeks before PMSG administration. Diabetic animals were given s.c. injections of $\sim 1 \mathrm{U}$ ultralente insulin (Lilly, Indianapolis, IN, USA) every $12 \mathrm{~h}$. Insulin was administered for at least 3 days before PMSG administration.

Recovery of zygotes. To assess pre-implantation embryo development of NOD mice in vitro, and after $72 \mathrm{~h}$ in vivo, 23 NOD animals were killed by cervical dislocation $72 \mathrm{~h}$ after $\mathrm{hCG}$ administration and mating. Embryos were flushed from the oviduct by introducing a blunted 30-gauge needle into the tubal ostium and injecting Ham's F-10 medium containing bovine serum albumin (BSA: Sigma, St Louis, MO, USA). Embryos were collected and identified. Since 1-cell structures include unfertilized oocytes and zygotes that could not be morphologically differentiated, we used the ratio of 1-cell structures to the total number of 1-cell structures plus embryos to assess in-vivo embryo development.

In-vitro development of zygotes. The embryos other than 1-cell structures ranged in developmental stage from 4-cell to morula. To assess in-vitro development, these recovered embryos (Group 2) were examined under a microscope, counted and pooled on the day of experimentation from mice that were non-diabetic, diabetic, or diabetic and treated with insulin. Embryos were placed in $1 \mathrm{ml}$ of Ham's F-10 medium with $0.1 \%$ BSA in groups of $15-30$ embryos/dish. The embryos were incubated for $72 \mathrm{~h}$ at $37^{\circ} \mathrm{C}$ in an atmosphere of $5 \% \mathrm{CO}_{2}, 5 \% \mathrm{O}_{2}$ and $90 \% \mathrm{~N}_{2}$. Development was evaluated every $24 \mathrm{~h}$ for a total of $72 \mathrm{~h}$. The number of blastomeres, as well as signs of degeneration or abnormal development as manifested by the swelling of the cell or the appearance of intracellular vacuoles, were observed at each time. Embryos were assigned to the following developmental stages: degenerated; 1, 2, 4, 5, 6, 7 or 8 blastomeres; morula; blastocyst; or expanded blastocysts.

In-vivo development of zygotes. Later in-vivo development was assessed in mice (Group 1) that were non-diabetic, diabetics not treated with insulin, or diabetics treated with insulin. Animals were killed $120 \mathrm{~h}$ after hCG administration and mating (compared with $72 \mathrm{~h}$ in Group 2). Embryos were recovered in the manner used in the in-vitro study, except that oviducts were flushed with the uterine horns attached to ensure recovery of all embryos reaching the uterine cavity, but not yet implanted. No implantation sites were seen in any of the uterine horns examined grossly. These embryos were then collected and pooled and the stages of development identified. This distribution of developmental stages, reflecting in-vivo development at $120 \mathrm{~h}$ after fertilization, was compared in non-diabetic and diabetic NOD mice.

Statistical analysis. Student's $t$ test, $\chi^{2}$ analysis and two-way analysis of variance of the average rank of sums in a randomized block design were used. The two-way analysis allowed comparison of embryo development on each day of observation, as well as comparison of the rate of development between the respective groups. Values are expressed as means \pm s.e.m. Statistical significance was defined as $P<0.05$. Observers were unaware of the identity of the different groups of embryos, which were randomly assigned numbers after being placed in different Petri dishes.

\section{Results}

\section{Development at recovery: early in-vivo development}

At $72 \mathrm{~h}$ after hCG administration, there was a greater percentage of 1 -cell structures ( $25 \mathrm{vs} .7 \%$ ) and a lower percentage of more mature embryos (75 vs. 93\%) in NOD diabetic mice than in non-diabetic NOD mice (Table 1), indicating significant impairment in the normal developmental progression $(P<0 \cdot 001)$. In-vivo insulin administration ameliorated this maturational delay. The percentage of 1-cell structures in diabetic NOD mice receiving insulin was significantly lower than that in the untreated diabetic animals (6 vs. $25 \%$ ) and a greater percentage of the total number of recovered structures had progressed further to a $\geqslant 4$-cell stage ( 94 vs. $75 \%$ ). There was no significant difference in the percentage of 1-cell structures or in the percentage of more mature embryos between non-diabetic NOD mice and diabetic NOD mice in which glucose concentrations had been reduced with insulin.

\section{In-vitro growth of embryos from non-diabetic and diabetic NOD mice}

Embryos recovered from non-diabetic NOD mice demonstrated significant progressive development over the $72 \mathrm{~h}$ of observation (Fig. 1, $P<0.0001$ ). Moreover, the development of 
Table 1. Distribution of 1-cell structures among the total number of recovered embryos collected $72 \mathrm{~h}$ after hCG administration and mating from 3 types of mouse

\begin{tabular}{|c|c|c|c|c|c|c|}
\hline \multirow[b]{2}{*}{ Mice } & \multirow{2}{*}{$\begin{array}{l}\text { Blood } \\
\text { glucose } \\
\text { (mg/dl) }\end{array}$} & \multirow{2}{*}{$\begin{array}{l}\text { No. of } \\
\text { mice }\end{array}$} & \multicolumn{2}{|c|}{ 1-cell } & \multicolumn{2}{|c|}{$\begin{array}{l}\text { More- } \\
\text { mature stage }\end{array}$} \\
\hline & & & $n$ & $(\%)$ & $n$ & $(\%)$ \\
\hline $\begin{array}{l}\text { Non-diabetic NOD } \\
\text { (ND) }\end{array}$ & $60-120$ & 7 & 7 & (7) & 95 & (93) \\
\hline $\begin{array}{l}\text { Diabetic NOD }{ }^{a} \text { no } \\
\text { insulin (D) }\end{array}$ & $180-800$ & 9 & 23 & (25) & 68 & (75) \\
\hline $\begin{array}{l}\text { Diabetic NODa } \\
\text { given insulin (DI) }\end{array}$ & $60-120$ & 7 & 5 & (6) & 80 & (94) \\
\hline
\end{tabular}

embryos recovered from non-diabetic NOD mice was not significantly different from that in embryos recovered from the $\mathrm{B}_{6} \mathrm{C}_{3} \mathrm{~F}_{1}$ mice. Embryos from the diabetic NOD mice exhibited significantly impaired development over $72 \mathrm{~h}$ in culture compared with embryos from non-diabetic NOD mice. This distribution of developmental stages was significantly different at each observation time (all $P<0.001$ ). Furthermore, by $72 \mathrm{~h}$, only 28 of $68(41 \%)$ of the embryos from diabetic animals had reached an expanded blastocyst stage compared with 68 of $81(84 \%)$ in the group of embryos from non-diabetic NOD mice. The slowing of the overall rate of development of embryos from diabetic mice was due to a progressive retardation that increased with time $(P<0.01)$.

\section{Effect of in-vivo insulin therapy on embryo development}

In-vivo insulin administration reversed the delay in development previously seen among the embryos from diabetic animals (Fig. 1). Both the progressive distribution of developing stages and the overall development rate were significantly accelerated among embryos in these animals (24, 48, $72 \mathrm{~h}$, all $P<0.001$ for distribution, $P<0.01$ for rate); but no significant differences existed between developmental rates among embryos from the insulin-treated diabetic mice, the non-diabetic NOD mice and control mice.

\section{Late in-vivo development}

In the mice killed $120 \mathrm{~h}$ after hCG administration and mating, embryo development in vivo was retarded in the diabetic mice. The distribution of developmental stages of embryos from nondiabetic NOD mice was significantly different from that in untreated diabetic NOD mice (Table 2): $92 \%$ of the embryos removed from the non-diabetic animals after $120 \mathrm{~h}$ had progressed in vivo beyond the morula stage, compared with $0 \%$ among the embryos from the uncontrolled diabetic animals $(P<0 \cdot 001)$. In the animals treated with insulin, this delay in embryo maturation was reversed: $90 \%$ of the 29 embryos recovered had advanced beyond the morula stage $(P<0.002$ compared with untreated diabetics).

Age appeared to have no significant effect on embryo development. The difference in overall development between embryos from the oldest (12 months) or youngest ( 6 weeks) non-diabetic animals, or between the oldest (11 months) and youngest ( 6 weeks) diabetic NOD mice was not statistically significant. 

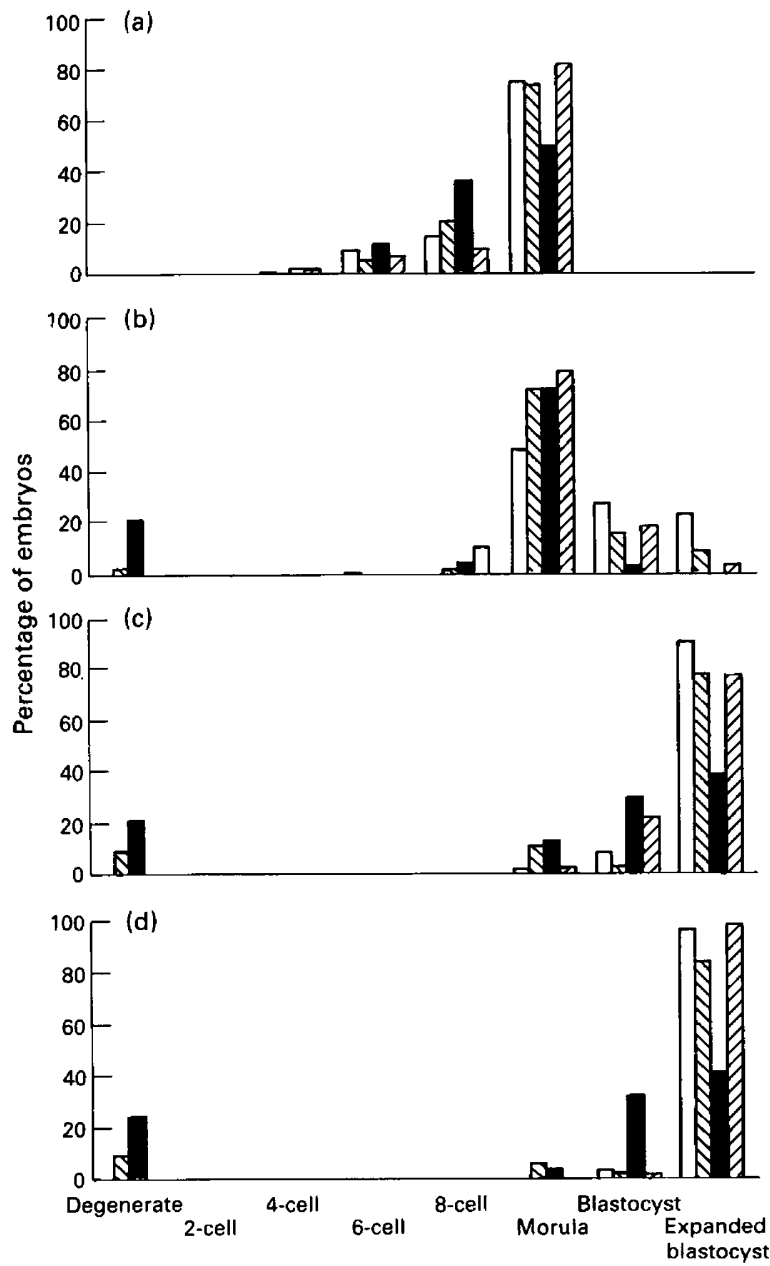

Fig. 1. Distribution of developmental stages (a) at time of recovery and after (b) 24 , (c) 48 or (d) $72 \mathrm{~h}$ of in-vitro culture of pre-implantation embryos recovered from non-diabetic $F_{1}$ hybrid mice ( $\square ; 17$ mice, 175 embryos), non-diabetic NOD mice ( $\mathbb{\$} ; 7$ mice, 81 embryos), diabetic NOD mice ( $\square ; 9$ mice, 68 embryos) and diabetic NOD mice treated with insulin $(\square ; 7$ mice, 71 embryos).

\section{Discussion}

Diamond et al. (1989) characterized the effect of chemically induced maternal diabetes on in-vivo and in-vitro pre-implantation embryo development. These studies revealed an in-vivo delay, as demonstrated $72 \mathrm{~h}$ after fertilization by an increased percentage of 1 -cell structures. This developmental retardation continued to be manifested in vitro throughout early embryo development. Invivo insulin therapy and concurrent lowering of blood glucose concentration partly reversed both the in-vivo and in-vitro delays seen among the embryos from diabetic animals. This finding thus implied that uncontrolled diabetes might adversely affect pregnancy outcome at the earliest stages of development. 
Table 2. Distribution of developmental stages of embryos $120 \mathrm{~h}$ after hCG administration and mating at time of recovery among 3 types of mouse

\begin{tabular}{|c|c|c|c|c|c|c|c|c|c|c|}
\hline \multirow[b]{2}{*}{ Mice } & \multirow{2}{*}{$\begin{array}{l}\text { Blood } \\
\text { glucose } \\
\text { (mg/dl) }\end{array}$} & \multirow{2}{*}{$\begin{array}{l}\text { No. of } \\
\text { mice }\end{array}$} & \multicolumn{8}{|c|}{ Embryo stage } \\
\hline & & & Deg & 4 & 6 & 8 & $\mathbf{M}$ & B & $\mathrm{EB}$ & $\mathrm{HB}$ \\
\hline $\begin{array}{l}\text { Non-diabetic NOD } \\
\text { (ND) }\end{array}$ & $60-120$ & 10 & $\begin{array}{c}9 \\
(8)\end{array}$ & & & & & & $\begin{array}{c}73 \\
(62)\end{array}$ & $\begin{array}{r}35 \\
(30)\end{array}$ \\
\hline $\begin{array}{l}\text { Diabetic NOD }{ }^{a} \text { no } \\
\text { insulin (D) }\end{array}$ & $180-800$ & 6 & $\begin{array}{c}97 \\
(84)\end{array}$ & $\begin{array}{l}10 \\
(9)\end{array}$ & $\begin{array}{c}3 \\
(3)\end{array}$ & $\begin{array}{c}1 \\
(1)\end{array}$ & $\begin{array}{c}4 \\
(3)\end{array}$ & & & \\
\hline $\begin{array}{l}\text { Diabetic NOD }{ }^{\text {a given }} \\
\text { insulin (DI) }\end{array}$ & $60-120$ & 2 & & & & & $\begin{array}{c}3 \\
(10)\end{array}$ & $\begin{array}{c}4 \\
(14)\end{array}$ & $\begin{array}{c}9 \\
(31)\end{array}$ & $\begin{array}{c}13 \\
(45)\end{array}$ \\
\hline
\end{tabular}

${ }^{a} P<0.001$, ND vs. D vs. DI (ND vs. D, $P<0.001$, ND vs. DI, NS; D vs. DI, $P<0.001$ ). Embryo development was graded as number (percentage) of embryos at each of the developmental stages: Deg $=$ degenerated, $4=$ four-cell, 6 = six-cell, $8=$ eight-cell, $\mathrm{M}=$ morula, $\mathrm{B}=$ blastocyst, $\mathrm{EB}=$ expanded blastocyst, $\mathrm{HB}=$ hatched blastocyst without zona.

Because our earlier studies used chemically induced diabetic mouse models, we investigated here spontaneously diabetic NOD mice to exclude a potential toxic effect of alloxan and streptozotocin on embryo maturation. In this study, embryos from the spontaneously diabetic NOD mice exhibited a marked impairment in early in-vivo development. The distributions of 1-cell structures and more advanced embryos ( $\geqslant 4$-cell stage) recovered $72 \mathrm{~h}$ after hCG administration and mating were significantly different among diabetic and non-diabetic NOD mice. This delay in early in-vivo developmental progression persisted and was also evident in late in-vivo development among the animals killed $48 \mathrm{~h}$ later or $120 \mathrm{~h}$ after mating. In-vivo insulin therapy appeared to reverse this invivo maturational delay seen at both 72 and $120 \mathrm{~h}$ after mating, i.e. no significant difference existed in the distribution of developmental stages between embryos from non-diabetic and insulin-treated diabetic animals. Since measurements of numbers of embryo cells represent a static examination of a dynamic process, such results do not fully characterize the event. None the less, this observation not only confirms what was shown in prior studies, but also extends our earlier finding by demonstrating the persistence of this growth retardation in vivo.

Subsequent in-vitro development of the embryos recovered from diabetic and non-diabetic NOD mice showed that, despite removal of the embryos from the mother, their development was still significantly retarded compared with those from non-diabetic NOD mice cultured under the same in-vitro conditions. These findings illustrate that the in-vivo maternal diabetic state, during the pre- and earliest post-conception period, may have a deleterious (and even permanent) effect on pre-implantation embryo development. This is not to say that the embryo after this event is then immune, in the in-vivo model, to any additional external forces, namely hyperglycaemia or other increases in metabolic intermediaries. On the contrary, our prior investigations showed that in-vitro conditions of hyperglycaemia and hyperketonemia markedly impair development in pre-implantation mouse embryos recovered from non-diabetic animals (Moley et al., 1988; Diamond et al., 1990). This implies that the impaired in-vivo development seen here in embryos recovered from diabetic mice $120 \mathrm{~h}$ after mating is an additive effect of some early deleterious event in combination with continuous exposure to hyperglycaemia and other embryopathic, metabolic derangements.

The mechanism of this developmental delay is not clear. Many studies have examined substrate utilization in developing mouse embryos. Zygotes incubated in pyruvate or oxaloacetate undergo normal cleavage at rates of 75 and 54\%, respectively (Biggers et al., 1967). Zygotes incubated in glucose, lactate or malate alone, however, failed to progress to a 2-cell stage. Moreover, glucose is not utilized by mouse embryos as a metabolic substrate until the 8-cell stage (Biggers et al., 1967). It appears, therefore, that hyperglycaemia may not be the sole inciting event leading to the developmental delays seen in embryos from the NOD mice, since growth retardation was seen before the 
8-cell stage in the in-vitro and early in-vivo groups. This may reflect an accumulation of metabolic intermediates within the developing embryo or an imbalance of the oxidative, reductive potential and energy source of the developing embryo. Freinkel (1980) used the term 'fuel-mediated teratogenesis' to describe the effect in the older fetus of the maternal metabolic fluxes, greatly exaggerated in the diabetic gravid female. Such a condition may also apply to the earlier embryo developmental stages.

Alternatively, the lack of insulin has also been implicated in early embryo development delay. The presence of insulin in an in-vitro culture stimulates growth and development in a 2-day chick model in a dose-dependent manner, while insulin antibodies cause growth retardation and degeneration of early chick embryos (dePablo et al., 1985). In-vitro studies of 2-cell mouse embryos, however, failed to demonstrate any growth-enhancing effects of direct insulin exposure (Diamond et al., 1991). Rather, correction of the metabolic imbalance by maternal insulin administration has been implicated in the resolution of the growth retardation.

We thank J. Andrews for typographical preparation of the manuscript.

\section{References}

Biggers, J.D., Whittingham, D.G. \& Donahue, R.P. (1967) The pattern of energy metabolism in the mouse oocyte and zygote. Proc. Natl Acad. Sci., USA 58, 560-567.

Coustan, D.R., Berkowtiz, R.L. \& Hobbins, J.L. (1980) Tight metabolic control of overt diabetes in pregnancy. Am. J. Med. 68, 845-852.

dePablo, F., Girbau, M. Gomez, J.A., Hernandez, E. \& Roth, J. (1985) Insulin antibodies retard and insulin accelerates growth and differentiation in early embryos. Diabetes 34, 1063-1067.

Diamond, M.P., Shah, D.M., Hester, R.A., Vaughn, W.K., Cotton, R.B. \& Boehm, F.H. (1985) Complications of insulin-dependent diabetic pregnancies by preeclampsia and/or chronic hypertension: analysis of outcome. Am. J. Perinatol. 2, 263-267.

Diamond, M.P., Salyer, S.L., Vaughn, W.K. \& Boehm, F.H. (1986) Congenital anomalies in offspring of insulin-dependent diabetic mothers. Diabetes Educat. 12, 272-276.

Diamond, M.P., Salyer, S.L., Vaughn, W.K., Cotton, R. \& Boehm, F.H. (1987) Reassessment of White's classification and Pedersen's prognostically bad signs of diabetic pregnancies in insulin-dependent diabetic pregnancies. Am. J. Obstet. Gynecol. 156, 599-604.

Diamond, M.P., Moley, K.H., Pellicer, A., Vaughn, W.K. \& DeCherney, A.H. (1989) Effects of streptozotocin and alloxan induced diabetes mellitus on mouse follicular and early embryo development. $J$. Reprod. Fert. 86, $1-10$.

Diamond, M.P., Harbert-Moley, K., Logan, J., Pellicer, A., Lavy, G. \& DeCherney, A.H. (1990) Manifestation of diabetes mellitus on mouse follicular and pre-embryo development: effect of hyperglycemia per se. Metabolism 39, 220-224.

Diamond, M.P., Pettway, Z.Y., Logan, J., Moley, K.H., Vaughn, W., DeCherney, A.H. (1991) Dose response effects of glucose, insulin and glucagon on mouse pre-embryo development. Metabolism 40, $566-570$.

Freinkel, N. (1980) Banting Lecture 1980, of pregnancy and progeny. Diabetes 29, 1023-1035.
Johnson, L.M. \& Sidman, R.L. (1979) A reproductive endocrine profile in the diabetes $(\mathrm{db})$ mutant mouse. Biol. Reprod. 20, 552-559.

Jovanovic, L., Druzin, M. \& Peterson, C.M. (1981) Effect of pregnancy in insulin-dependent diabetic women as compared with normal control subjects. Am. J. Med. 71, 921-927.

Kano, Y., Kanatsuna, T., Nakamura, N., Kitagawa, Y., Mori, H., Kajiyama, S., Nakano, K. \& Kondo, M. (1986) Defect of the first-phase insulin secretion to glucose stimulation in the perfused pancreas of the non-obese diabetic (NOD) mouse. Diabetes 35, 486-490.

Kitzmiller, J.L., Cloherty, J.P., Younger, M.D., Tabatabaii, A., Rothchild, S.B., Sosenko, I., Epstein, M.F., Singh, S. \& Neff, R.K. (1978) Diabetic pregnancy and perinatal morbidity. Am. J. Obstet. Gynecol. 131, 560-580.

Lawrence, L.A. \& Cantalopoulos, A.N. (1960) Reproductive performance in the alloxan diabetic female rat. Acta endocr., Copnh. 33, 175-184.

Makino, S., Kurimoto, K., Muraoka, Y., Mizushima, Y., Katagiri, K. \& Tochino, Y. (1980) Breeding of a non-obese diabetic strain of mice. Exp. Anim. 29, 1-13.

Makino, S., Kurimoto, K., Muraoka, Y. \& Katagiri, K. (1981) Effect of castration on the appearance of diabetes in the NOD mouse. Exp. Anim. 30, 137-140.

Miodovnik, M., Lavin, J., Knowles, H., Holyrode, S. \& Stys, S. (1984) Spontaneous abortion among insulindependent diabetic women. Am. J. Obstet. Gynecol. 150, 372-376.

Miodovnik, M., Skilman, C., Holroyde, J.C., Butler, J.B., Wendel, J.S. \& Siddiqi, T.A. (1985) Elevated maternal glycohemoglobin in early pregnancy and spontaneous abortion among insulin-dependent diabetic women. Am. J. Obstet. Gynecol. 153, 439-442.

Moley, K.H., Diamond, M.P., Pellicer, A., Vaughn, W.K. \& DeCherney, A.H. (1988) Effects of metabolic intermediates on pre-embryo development. Abstract, presented at the 44th Annual Meeting, American Fertility Society, Atlanta, GA, USA. 
Moley, K.H., DeCherney, A.H., Vaughn, W.K. \& Diamond, M.P. (1989) Impaired development of preembryos from a spontaneous diabetic animal, the non-obese diabetic (NOD) mouse: resolution by maternal in vivo insulin therapy. (abstr.) Thirty-Sixth Annual Meeting of the Society of Gynecologic Investigation, San Diego, CA, USA.

Pederson, J.F. \& Molsted-Pederson, L. (1979) Early growth retardation in diabetic pregnancy. Br. Med.J. I, 18-19.

Pederson, J.F. \& Molsted-Pederson, L. (1981) Early fetal growth delay detected by ultrasound marks increased risk of congenital malformation in diabetic pregnancy. Br. Med. J. 283, 269-271.
Sheridan-Pereira, M., Drury, M., Baumgart, R., UaConaill, D. \& France, M. (1983) Haemoglobin $A_{1}$ in diabetic pregnancy: an evaluation. Isr. J. Med. Sci. 152, 261-267.

Simpson, J.L., Elias, S., Martin, A.O., Palmer, M.S., Ogata, E.S. \& Ragvany, R.A. (1983) Diabetes in pregnancy, Northwestern University series (19771981). I. Prospective study of anomalies in offspring of mothers with diabetes mellitus. Am. J. Obstet. Gynecol. 146, 263-270.

Received 20 August 1990 